\title{
Retail Potential for Upcycled Foods: Evidence from New Zealand
}

\author{
Francesca Goodman-Smith ${ }^{1,2}$, Siddharth Bhatt ${ }^{3}$, Robyn Moore ${ }^{2}$, Miranda Mirosa ${ }^{1, * \mathbb{D}}$, Hongjun Ye $^{4} \mathbb{D}$, \\ Jonathan Deutsch 5 (i) and Rajneesh Suri ${ }^{4}$
}

check for updates

Citation: Goodman-Smith, F.; Bhatt,

S.; Moore, R.; Mirosa, M.; Ye, H.; Deutsch, J.; Suri, R. Retail Potential for Upcycled Foods: Evidence from New Zealand. Sustainability 2021, 13, 2624. https://doi.org/10.3390/ su13052624

Academic Editors: Pedro Miguel Capêlo da Silva and Jorge Dinis Câmara Freitas

Received: 8 February 2021 Accepted: 23 February 2021 Published: 1 March 2021

Publisher's Note: MDPI stays neutral with regard to jurisdictional claims in published maps and institutional affiliations.

Copyright: (c) 2021 by the authors. Licensee MDPI, Basel, Switzerland. This article is an open access article distributed under the terms and conditions of the Creative Commons Attribution (CC BY) license (https:// creativecommons.org/licenses/by/ $4.0 /)$.
1 Department of Food Science, University of Otago, Dunedin 9016, New Zealand; f.goodmansmith@gmail.com 2 Foodstuffs NZ Ltd., Auckland 2022, New Zealand; robyn.moore@foodstuffs.co.nz

3 School of Business Administration, Pennsylvania State University at Harrisburg, 777 West Harrisburg Pike, Middletown, PA 17057, USA; shb5170@psu.edu

4 LeBow College of Business, Drexel University, 3141 Chestnut Street, Philadelphia, PA 19104, USA; hy368@drexel.edu (H.Y.); surir@drexel.edu (R.S.)

5 College of Nursing and Health Professions, Drexel University, 3141 Chestnut Street, Philadelphia, PA 19104, USA; st96d633@drexel.edu

* Correspondence: miranda.mirosa@otago.ac.nz

\begin{abstract}
Food waste is a problem that manifests throughout the food supply chain. A promising solution that can mitigate the food waste problem across various stages of the food supply chain is upcycling food ingredients that would otherwise be wasted by converting them into new upcycled food products. This research explores perception of upcycled foods from a panel of 1001 frequent shoppers at a large grocery retailer in New Zealand. Findings from this research uncover several hitherto unexamined aspects of consumers' evaluations of upcycled foods. These include consumers' indications about shelf placements of upcycled foods, willingness to buy upcycled foods for people or pets other than themselves, and consumers' preferences about information pertaining to these foods. This research advances our understanding of how consumers perceive upcycled foods and provides actionable insights to practitioners in the food industry.
\end{abstract}

Keywords: food waste; upcycled foods; food marketing; food retailing; sustainability

\section{Introduction}

Food waste is a problem that occurs at all levels of the food supply chain. A promising solution that can mitigate the food waste problem across various stages of the food supply chain, at least in part, is upcycled foods. Spratt et al. [1], suggest that-“ 'Upcycled ingredients and food products elevate food that would otherwise be wasted to higher uses and have tangible benefits to the environment and society." Similarly, Upcycled Food Association (UFA) defines upcycled foods as those- "that use ingredients that otherwise would not have gone to human consumption, are procured and produced using verifiable supply chains, and have a positive impact on the environment." In essence, upcycled foods use food ingredients that would otherwise be discarded. For instance, soup made from carrot peels or a cereal bar made from spent grain resulting from beer brewing are examples of upcycled foods [2-4].

A small but growing body of literature points to consumer acceptance of upcycled foods. Starting with research by Bhatt et al. [2], other researchers have found that upcycled foods may be gaining acceptance among consumers [4-7]. It is not surprising that food manufacturers have started introducing upcycled foods into the market. Brands such as Regrained (regreained.com) and Planeterians (planetarians.com) sell foods made from upcycled ingredients in the United States. Upcycled foods are beginning to emerge in markets across the globe, including in New Zealand were upcycled products from Citizen Collective (upcycled beer), and Perfect Deli Fresh (upcycled pet food) 
are now available in supermarkets. A recent survey by Colmar Brunton, a market research company in New Zealand showed $70 \%$ of consumers are searching for sustainable choices and $67 \%$ want to make environmentally conscious decisions, even if the cost is greater (https:/ / static.colmarbrunton.co.nz/wp-content/uploads/2019/05/ColmarBrunton_Better-Futures-2020-Presentation.pdf, accessed on 8 February 2021).

Emergence of brands that focus on creating and commercializing upcycled foods is a positive development. However, a wider interest from food industry practitioners in creating a market for such foods will largely depend on consumer response. Bhatt et al. [2], found that although there are various promising aspects to upcycled foods, some reluctance by consumers to consume foods made from products perceived as waste may exist. Understanding consumers underlying concerns and purchasing desires is essential to drive consumer interest in upcycled foods, which will in turn propel a demand that food manufacturers and their supply chain partners will be keen to fulfil. Besides, researchers have recently called for a change in the food retail industry so that this industry could become a participant in the global efforts to make food consumption healthier and more sustainable [8]. Hence, at this early stage, it is necessary to examine how consumers feel about buying and consuming upcycled foods. This research explores aspects of acceptance of upcycled foods among a panel of consumers in New Zealand. This study was conducted by Foodstuffs which is a major food retail chain in New Zealand. Foodstuffs canvassed the views of over 1001 of their frequent shoppers to better understand shoppers' interests, motivations, apprehensions, and potential behaviours of trial and purchase of upcycled foods. In doing so, our goal was to conduct research that is accessible and meaningful for practitioners in the food industry. The aim was to investigate the most pertinent aspects of consumer evaluation of upcycled foods that have direct implications for practitioners interested in manufacturing and marketing these foods.

The current research advances the literature on upcycled foods on three fronts. First, while there have been studies on consumer perceptions of upcycled foods in the United States [1-4,9] and Europe [5-7,10-14], this research is the first with shoppers in New Zealand. Second, most research on this topic has relied on small samples in laboratory-like settings. This research employs a large panel of 1001 shoppers at Foodstuffs. Third, this research explores many aspects of consumer perception and behaviour that have not been examined in past research on upcycled foods. These include consumers' indications about shelf placements of upcycled foods, willingness to buy upcycled foods for people other than themselves, willingness to buy upcycled foods for pets, and consumers' preferences about information disclosure by sellers of these foods. Although exploratory in nature, this research advances our understanding of how consumers perceive upcycled foods and provides actionable insights to practitioners in the food industry.

\section{Methods}

An exploratory survey consisting of a series of questions was developed by the Foodstuffs New Zealand sustainability and market insights teams in conjunction with academics from United States and New Zealand with expertise in upcycling food waste, marketing research and survey design, and consumer behavior. Questions covered three main themes: general awareness of upcycled foods, drivers and concerns contributing towards attitudes about upcycled foods, and anticipated purchasing behavior relating to upcycled foods. Using the online survey tool Yabble, consumers who shop at Foodstuffs stores (New World, a premium supermarket brand, and PAK'nSAVE, a value supermarket brand) and subscribe to Yabble as market research participants were invited to complete the survey. Sampling was not designed to be representative of the population or stratified by income. The participant recruitment approach was designed to gain insight into the attitudes of existing Foodstuffs shoppers rather than the population as a whole. To qualify for the survey, participants needed to be either the main or joint household grocery shopper and be over the age of 18 years. A total of 1001 respondents (see Table 1) completed the survey with the incentive of entering a prize draw to win one of four $\$ 50$ supermarket 
vouchers; a customary incentive used for research. The survey was conducted from 17-25 August 2020 during COVID-19 Pandemic Alert Level 3 (Auckland) and Level 2 (rest of New Zealand); Alert Level 3 requiring people to stay home if they can to avoid any risk of spread and Alert Level 2 allowing people to go to work and school. While the research was not COVID-19 specific, given global events, it is an important context for the research.

Table 1. Demographic characteristics of participants $(n=1001)$.

\begin{tabular}{|c|c|c|c|}
\hline Characteristic & $\begin{array}{l}\text { Females } \\
(n=751)\end{array}$ & $\begin{array}{c}\text { Males } \\
(n=248)\end{array}$ & $\begin{array}{c}\text { Gender Diverse } \\
(n=2)\end{array}$ \\
\hline \multicolumn{4}{|l|}{ Age (y) } \\
\hline $20-34$ & 50 & 14 & 1 \\
\hline $35-54$ & 224 & 50 & - \\
\hline $55-65$ & 197 & 50 & 1 \\
\hline$>65$ & 280 & 134 & - \\
\hline \multicolumn{4}{|l|}{ Household situation $^{1}$} \\
\hline Young couple/no kids & 41 & 12 & - \\
\hline Young family & 84 & 24 & - \\
\hline Older family & 152 & 44 & 1 \\
\hline Older single or couple no kids (at home) & 401 & 149 & - \\
\hline Group flatting & 16 & 9 & - \\
\hline Other & 55 & 9 & 1 \\
\hline \multicolumn{4}{|l|}{ Shopper } \\
\hline Main household shopper & 618 & 133 & 1 \\
\hline Joint household shopper & 133 & 115 & 1 \\
\hline \multicolumn{4}{|l|}{ Shopping frequency } \\
\hline Daily & 12 & 7 & - \\
\hline 2-3 times per week & 225 & 83 & 2 \\
\hline Once per week & 399 & 123 & - \\
\hline Every $2-3$ weeks & 106 & 33 & - \\
\hline Once per month & 8 & 2 & - \\
\hline Every $2-3$ months & 1 & - & - \\
\hline
\end{tabular}

${ }^{1}$ One male and two females did not answer this question.

After collecting the survey responses, the data set was analyzed in Microsoft Excel (2011) using descriptive statistics, in particular measures of frequency. In the results section, the data is presented as percentages to show how often a particular response was given.

\section{Results}

The first in a series of questions was-“Have you ever heard of upcycled food?" (yes, no, do not know). Only 10\% of the respondents indicated that they had heard about upcycled foods while $84 \%$ of respondents indicated that they had not heard about upcycled foods. Next, they were shown a description of upcycled foods (see Appendix A). After participants viewed the description, they were asked-“If products containing upcycled ingredients were on the shelves at the supermarket, how likely would you be to consider trying or buying such products?". Fifty-six percent of participants indicated they would not hesitate to buy such products while $25 \%$ of participants indicated they would try or buy them with some hesitation. Only $6 \%$ participants indicated that they would not try or buy such products while $13 \%$ of participants were unsure. This preliminary finding is encouraging to manufacturers and marketers of upcycled foods, in that many shoppers are willing to try or buy products with upcycled ingredients. Participants were also asked-“Who would you be likely to buy upcycled food products for?". Seventy percent of participants indicated they would buy upcycled foods for themselves. Fifty percent of participants indicated they would buy for others in the household, $28 \%$ indicated they would buy for their pets, $18 \%$ indicated they would buy for their children, and $20 \%$ indicated they were unsure. Further, participants responded to- "If a product similar to one you normally purchase was also available with upcycled food ingredients and everything 
else about the food product was the same (price, taste, size, etc.) would you be (more likely to purchase the upcycled food product, more likely to purchase the conventional food product, equal likelihood for both/either, do not know). Thirty-five percent of participants indicated that they were more likely to buy the upcycled food product while $34 \%$ of participants indicated an equal likelihood for both/either. Twenty-four percent of participants indicated they were more likely to buy conventional food product while $7 \%$ were unsure. The finding that $69 \%$ of participants are more or equally likely to buy upcycled food presents another promising result for the upcycled food industry.

Participants also answered questions aimed at assessing their perception of upcycled foods which could explain their willingness, or lack thereof, to try or buy upcycled foods. Participants were asked: "If a product contains upcycled food ingredients, does that make the upcycled product (more attractive, no more or less attractive, less attractive, do not know)." Twenty-two percent of participants indicated that they would find such a product more attractive, however only $12 \%$ of these shoppers would be prepared to pay more for upcycled food than conventional food (see Figure 1).

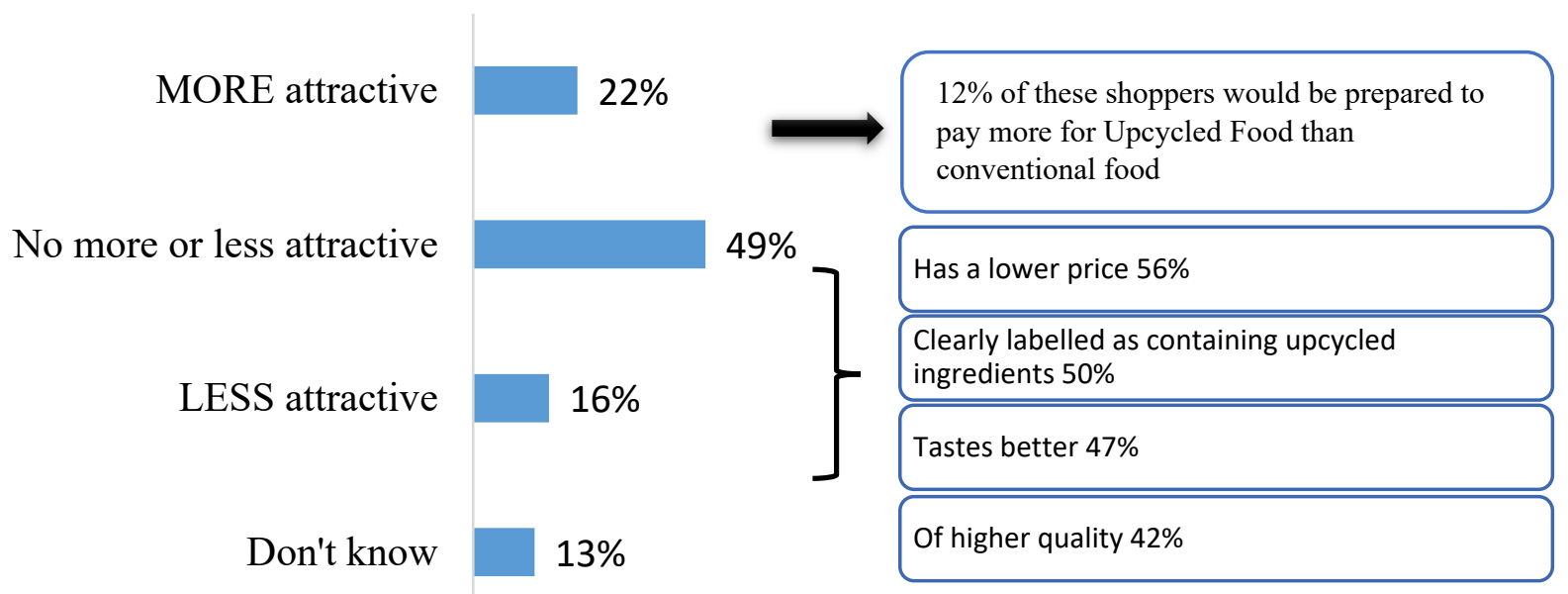

Figure 1. Attractiveness of Upcycled Foods vis-à-vis Conventional Foods.

While $49 \%$ of participants indicated that they would find the product no more or less attractive, only $16 \%$ of participants indicated that they would find the product less attractive. Of these participants who were negative or unsure about the attractiveness of upcycled products, $56 \%$ would find an upcycled product more attractive if it had a lower price, $47 \%$ noted increased interest if the product tastes better, $42 \%$ if the product was of higher quality, and $50 \%$ of these participants believe clear labelling that the product contains upcycled ingredients would increase attractiveness.

Again, this finding is encouraging to marketers because the majority of shoppers did not find upcycled food products less attractive than conventional food products.

Participants were also asked: "Please rate how important each of the following would be for you when considering trying or buying upcycled food products". On a categorical scale, they were asked to rate the importance of list of ingredients, country of origin, labelling, certification, industry of origin, and price (see Figure 2). 




Figure 2. Importance of information Regarding Upcycled Foods.

Two more questions were asked to assess the preferred retail execution of upcycled foods. Participants were asked-“If your local supermarket sold upcycled products as well as conventional products would you think (more positively about them, no more or less positively about them, less positively about them)." Fifty-four percent of participants indicated that they would view such a supermarket more positively while $43 \%$ of participants indicated that they would view such a supermarket no more or less positively. Only $3 \%$ of participants indicated that they would view the supermarket less positively. The finding that a very small percentage of shoppers view supermarkets carrying upcycled food less positively suggests that retailers should not be worried that upcycled foods will negatively impact their image. Participants were also asked to indicate where in the supermarket would they like to see upcycled foods. Fifty-two percent of participants indicated that they would like to see upcycled foods on the same shelves as conventional products. Thirty-eight percent of participants indicated that they would like to see upcycled foods in a section dedicated to such foods while $9 \%$ indicated that they would like to see upcycled foods in the special diet foods sections such as organic and gluten free products. Given that only $9 \%$ of participants perceive these foods to be more similar to special diet foods is also an encouraging finding for retailers.

\section{General Discussion}

Upcycled foods are a new food trend demonstrating substantial promise. In fact, Whole Foods Market, named upcycled foods in their top food trends for 2021 (https: / www. businesswire.com/news/home/20201019005038/en/Whole-Foods-Market-Forecasts-Top10-Food-Trends-for-2021, accessed on 8 February 2021). As per the Environmental Protection Agency (EPA), food recovery efforts that utilize ingredients that would otherwise be wasted are likely to be more beneficial compared to other efforts such as composting (https://www.epa.gov/sustainable-management-food/food-recovery-hierarchy, accessed on 8 February 2021). Responding to this call, academics and practitioners have begun to explore upcycled foods. The introduction of brands such as Regrained. Ugly Co., Spudsy, and Planetarians in the United States; Kaffe Bueno in Denmark; Remashed in the United Kingdom; and Citizen Collective, Perfect Deli Fresh, and déjà in New Zealand is evidence of early commercial interest in upcycled foods. Concurrently, in the last three years, a small body of academic literature has also emerged. Studies conducted in the United States and Europe show that consumer acceptance for upcycled foods can be shaped by understanding and guiding consumers' evaluation of these foods $[2-7,11,13,15]$. The findings of this study reinforce emerging awareness and positive consumer sentiments about upcycled foods. Although only $10 \%$ of participants had heard of upcycled foods 
prior to the survey, after the term was explained, more than three-quarters of shoppers stated they would be willing to try or buy upcycled foods.

Furthermore, the research team asked several questions pertaining to consumers' expectation regarding the information about these foods. Shoppers in the sample indicated that several pieces of information such as a complete list of ingredients used in the foods, to the country and industry of origin of such ingredients are critical cues for them when evaluating upcycled foods (see Figure 2). These are new findings that add to the general idea in Bhatt et al. [2], that consumers will rely on cues when evaluating this new category of foods. These findings also point to the fact that practitioners can shape consumers' assessment of upcycled foods by appropriately designing such cues. Labels and claims can be an effective way to build consumer confidence in a product and delineate value. Grunert, et al. [16], found that consumers associated environmental labels (i.e., carbon or land use) with sustainability of a product, more so than ethical labels (i.e., fair pay or child labor). Although consumers stated they were willing to pay up to a $10 \%$ premium for certain logos (i.e., Fair Trade), Grunert et al. [16], found this was not translated into purchasing behavior. Participants in Grunert et al. [16], identified the perceived high price of sustainable products to be a significant barrier to purchase.

We found that upcycled food becomes more attractive primarily through lower pricing and full ingredient disclosure, demonstrated by the result that $56 \%$ of those who were agnostic or initially viewed upcycled products less attractive than conventional products would find upcycled products more attractive if the price was lower, and 50\% would find them more attractive if they were clearly labelled that they contained upcycled ingredients (Figure 1). Only a small proportion of shoppers who consider upcycled food more attractive than conventional food would pay more for that upcycled food (Figure 1).

Past research has not examined the issue of who consumers buy these foods for. We found that many consumers are willing to buy such foods for other people in their household and their pets. This finding points to a possibility for creation and marketing of pet foods made with upcycled ingredients. Another aspect of consumer acceptance, hitherto unexamined, pertains to the image of the retailer carrying such foods. Retailers may be hesitant in carrying upcycled foods due to a concern that doing so would negatively impact their image in the minds of consumers. Our findings indicate that such a fear may be unfounded. Ninety-seven percent of shoppers in our sample indicated that they would view a supermarket carrying upcycled foods more positively or no less positively. Such preliminary findings should encourage retailers to explore carrying upcycled foods. Finally, we examined the equally important issue of shelf placement. We observed variance in participant preferences about where they would like to see upcycled foods inside a store. More than half of the respondents indicated that they would like to see upcycled foods next to conventional foods. A little over one-third of the respondents indicated that they would like to see a section dedicated to such foods. These findings provide actionable insights to food industry practitioners.

While past research contains promising findings, such research has largely investigated consumer perception of these foods in lab-like settings with small samples. We drew inspiration from the research by Albizzati, et al. [17], who examined the impact of valorisation of surplus foods at 20 retail outlets in France. Our research was conducted with a large panel of 1001 shoppers of a large food retailer in New Zealand. In addition to being the first study to be published on upcycled foods in New Zealand, the inquiry also benefited from a large sample of consumers.

A limitation of this research is that many questions offered prompted responses (i.e., participants were asked to rate the importance of list of ingredients, country of origin, labelling, certification, industry of origin, and price from a list provided (Figure 2)). It was therefore not possible to ascertain whether participants believed that these specific factors were important, or whether, due to the novelty of upcycled foods, they viewed any information provision as important. Another limitation of the present study was that real-life examples of upcycled foods available in New Zealand were not used to 
illustrate the concept of upcycled foods to consumers due to lack of product available on the New Zealand market at the time the research was carried out. Further, the survey was conducted during the COVID-19 pandemic. People lost their jobs and people all over the world started to pay attention to consumption. Although New Zealand's world-leading response may have protected New Zealanders from the full brunt of the pandemic, it should be acknowledged that the pandemic may have influenced consumer perceptions, particularly price sensitivity. There is a risk that the incentive for participation may have prompted consumers to tailor their responses, however an explanation soliciting honest opinions independent of the incentive draw was provided. Furthermore, there is no logical reason to think that-in the absence of incentives for participation-responses could have been different.

Future research should focus on the marketing around upcycled foods including education strategies to communicate benefits, labelling, certification, and pricing. Development of trust and understanding in upcycled food amongst consumers will be important through raising awareness about the environmental and societal benefits specific to the values of the consumer. To aid development of trust, upcycled food producers should consider soft launches and in store tastings of any new products [5]. Future research should focus on testing acceptance of real upcycled food products in a supermarket environment to gain deeper insights into consumer behavior, rather than hypothetical perceptions [11].

In sum, findings from this research provide practical and direct insights to industry practitioners who must play a key role in shaping consumer acceptance of upcycled foods. It also lays a foundation for future research with statistical modeling and transnational comparative studies. This research investigated some of the most pertinent aspects of consumer acceptance which include willingness to purchase, usage, key information expectations, retailer evaluation, and shelf placement. In doing so, our goal was to conduct actionable research that may be as accessible and interesting to practitioners in the food industry as it may be to food researchers. Our findings add to the existing literature on the commercial potential of upcycled foods and align with the consensus in extant literature that consumer acceptance of upcycled foods can be shaped.

Author Contributions: Conceptualization, F.G.-S.; methodology, F.G.-S. and R.M.; software, R.M.; validation, F.G.-S.; formal analysis, R.M.; investigation, F.G.-S. and S.B.; resources, R.M. and F.G.-S.; data curation, R.M.; writing - original draft preparation, S.B. and F.G.-S.; writing-review and editing, F.G.-S., S.B., M.M., H.Y., J.D., R.S.; visualization, F.G.-S., S.B., M.M., H.Y., J.D., R.S.; supervision, J.D. and M.M.; project administration, F.G.-S. All authors have read and agreed to the published version of the manuscript.

Funding: This research received no external funding.

Institutional Review Board Statement: The study was conducted according to the code of ethics for the Research Association of New Zealand and no other reviews or approval were required or applicable.

Informed Consent Statement: Informed consent was obtained from all subjects involved in the study.

Data Availability Statement: Restrictions apply to the availability of these data. Data was obtained from Foodstuffs NZ and are available from the authors with the permission of Foodstuffs NZ.

Conflicts of Interest: The authors declare no conflict of interest. 


\section{Appendix A}

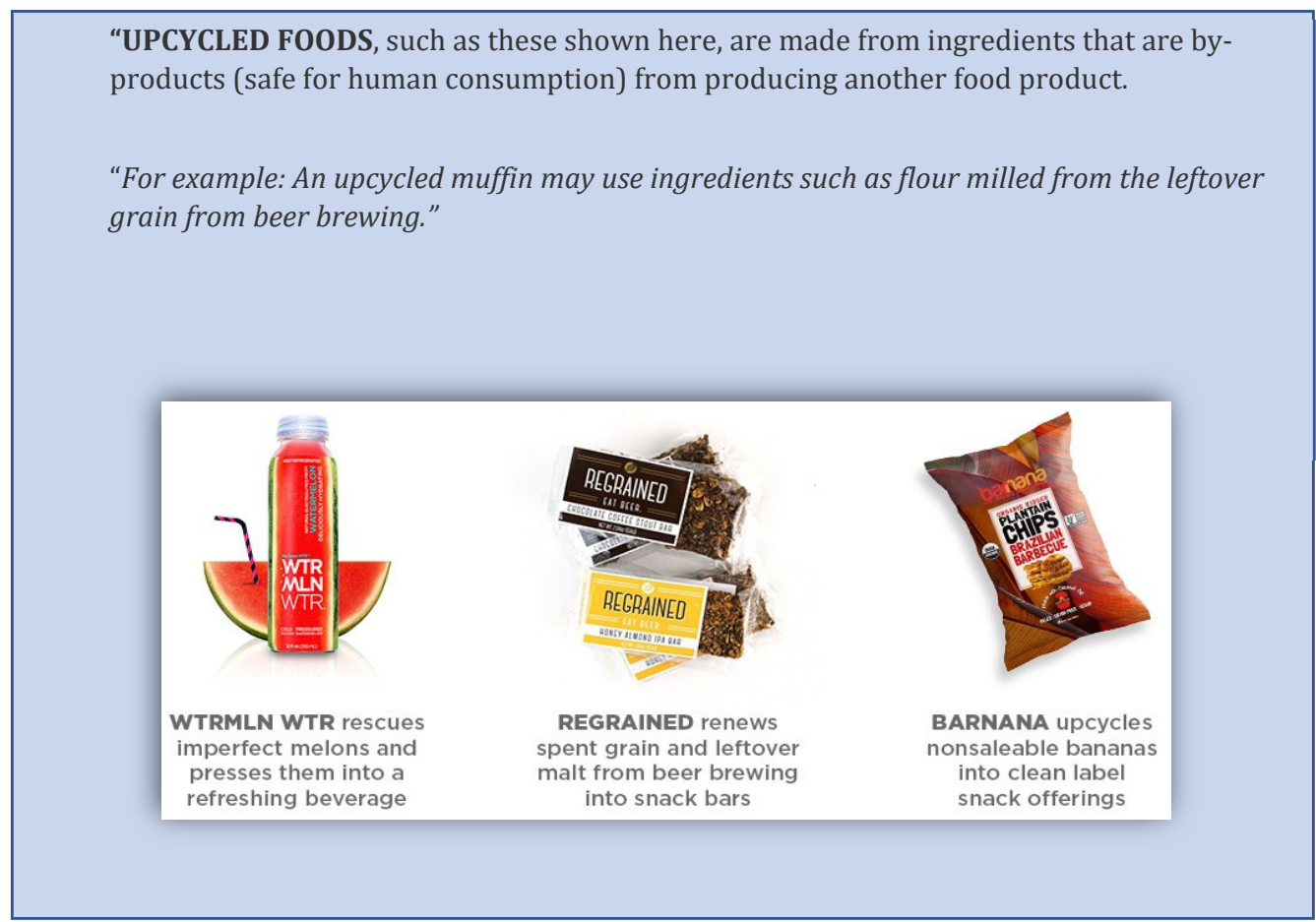

\section{References}

1. Spratt, O.; Suri, R.; Deutsch, J. Defining Upcycled Food Products. J. Culin. Sci. Technol. 2020, 1-12. [CrossRef]

2. Bhatt, S.; Lee, J.; Deutsch, J.; Ayaz, H.; Fulton, B.; Suri, R. From food waste to value-added surplus products (VASP): Consumer acceptance of a novel food product category. J. Consum. Behav. 2018, 17, 57-63. [CrossRef]

3. Bhatt, S.; Ye, H.; Deutsch, J.; Ayaz, H.; Suri, R. Consumers' willingness to pay for upcycled foods. Food Qual. Prefer. 2020, 86, 104035. [CrossRef]

4. Zhang, J.; Ye, H.; Bhatt, S.; Jeong, H.; Deutsch, J.; Ayaz, H.; Suri, R. Addressing Food Waste: How to Position Upcycled Foods to Different Generations. J. Consum. Behav. 2021. [CrossRef]

5. Aschemann-Witzel, J.; Peschel, A.O. How circular will you eat? The sustainability challenge in food and consumer reaction to either waste-to-value or yet underused novel ingredients in food. Food Qual. Prefer. 2019, 77, 15-20. [CrossRef]

6. Coderoni, S.; Perito, M.A. Sustainable consumption in the circular economy. An analysis of consumers' purchase intentions for waste-to-value food. J. Clean. Prod. 2020, 252, 119870. [CrossRef]

7. Peschel, A.O.; Aschemann-Witzel, J. Sell more for less or less for more? The role of transparency in consumer response to upcycled food products. J. Clean. Prod. 2020, 273, 122884. [CrossRef]

8. Moran, A.; Roberto, C. The Retail Food Environment: Time for a Change. Int. J. Environ. Res. Public Health 2020, $17,8846$. [CrossRef] [PubMed]

9. Combest, S.; Warren, C. Perceptions of college students in consuming whole grain foods made with Brewers' Spent Grain. Food Sci. Nutr. 2019, 7, 225-237. [CrossRef] [PubMed]

10. Cattaneo, C.; Lavelli, V.; Proserpio, C.; Laureati, M.; Pagliarini, E. Consumers' attitude towards food by-products: The influence of food technology neophobia, education and information. Int. J. Food Sci. Technol. 2019, 54, 679-687. [CrossRef]

11. Grasso, S.; Asioli, D. Consumer preferences for upcycled ingredients: A case study with biscuits. Food Qual. Prefer. 2020, 84, 103951. [CrossRef]

12. Nitzko, S.; Spiller, A. Comparing "Leaf-to-Root", “Nose-to-Tail” and Other Efficient Food Utilization Options from a Consumer Perspective. Sustainability 2019, 11, 4779. [CrossRef]

13. Perito, M.A.; Coderoni, S.; Russo, C. Consumer attitudes towards local and organic food with upcycled ingredients: An italian case study for olive leaves. Foods 2020, 9, 1325. [CrossRef] [PubMed]

14. Perito, M.A.; Di Fonzo, A.; Sansone, M.; Russo, C. Consumer acceptance of food obtained from olive by-products. Br. Food J. 2019, 122, 212-226. [CrossRef]

15. McCarthy, B.; Kapetanaki, A.B.; Wang, P. Completing the food waste management loop: Is there market potential for value-added surplus products (VASP)? J. Clean. Prod. 2020, 256, 120435. [CrossRef] 
16. Grunert, K.G.; Hieke, S.; Wills, J. Sustainability labels on food products: Consumer motivation, understanding and use. Food Policy 2014, 44, 177-189. [CrossRef]

17. Albizzati, P.F.; Tonini, D.; Chammard, C.B.; Astrup, T.F. Valorisation of surplus food in the French retail sector: Environmental and economic impacts. Waste Manag. 2019, 90, 141-151. [CrossRef] [PubMed] 